\title{
The effect of nonsurgical periodontal therapy on hepcidin and on inflammatory and iron marker levels
}

\begin{abstract}
Sandra Augusta de Moura LEITE(a) Rosana Costa CASANOVAS ${ }^{(a)}$ Vandilson Pinheiro RODRIGUES(a) iD Adriana de Fátima Vasconcelos PEREIRA $^{(a)}$
\end{abstract}

Teresa Cristina Alves FERREIRA ${ }^{(b)}$ Flávia Raquel Fernandes do NASCIMENTO(c)

Johnny Ramos do NASCIMENTO(c) Isaac Suzart GOMES-FILHO(d) iD Marcus Gomes BASTOS(e) ID

Antonio Luiz Amaral PEREIRA(a)

(a) Universidade Federal do Maranhão UFMA, Graduate Program in Dentistry, São Luís, MA, Brazil.

(b) Hospital Universitário da Universidade Federal do Maranhão - HUUFMA, São Luís, MA, Brazil.

(c) Universidade Federal do Maranhão UFMA, Graduate Program in Health Sciences, São Luís, MA, Brazil.

(d) Universidade Estadual de Feira de Santana - UEFS, Department of Health, Feira de Santana, BA, Brazil.

(e) Universidade Federal de Juiz de ForaUFJF, Department of Nephrology, Juiz de Fora, MG, Brazil.

Declaration of Interests: The authors certify that they have no commercial or associative interest that represents a conflict of interest in connection with the manuscript.

\section{Corresponding Author:}

Sandra Augusta Moura Leite

E-mail: leite.sandra@hotmail.com

hitps://doi.org/10.1590/1807-3107bor-2019.vol33.0055

Submitted: June 15, 2018

Accepted for publication: April 08, 2019

Last revision: June 12, 2019
Abstract: Serum hepcidin levels may increase in response to infection and inflammation. The present study investigated the effect of nonsurgical periodontal therapy (NSPT) on levels of serum hepcidin, inflammatory markers, and iron markers. An interventional study was conducted on 67 patients (age 30-65 years) without other diseases, except for chronic periodontitis (CP). Patients were allocated to either $\mathrm{CP}$ or control groups. The $\mathrm{CP}$ group received supragingival and subgingival scaling and root planing procedures, whereas the control group received supragingival scaling. Probing depth (PD), bleeding on probing, clinical attachment level (CAL), visible plaque index (VPI), serum hepcidin and interleukin-6 (IL-6) levels, highsensitivity C-reactive protein (hs-CRP), hematological markers, and iron markers were measured at baseline and at 90 days after NSPT. The CP group had statistically significant lower mean values for mean corpuscular volume (MCV) and mean corpuscular hemoglobin $(\mathrm{MCH})$ $(\mathrm{p} \leq 0.05)$. The control group had statistically significant reductions in hemoglobin, hematocrit, $\mathrm{MCV}$, and $\mathrm{MCH}$ ( $\mathrm{p} \leq 0.05$ ). Serum hepcidin, IL-6, and erythrocyte sedimentation rate (ESR) levels were significantly decreased in both groups after NSPT. Periodontal markers were more markedly reduced in the $\mathrm{CP}$ group compared with the control group ( $p \leq 0.05$ ). These findings suggest that NSPT may reduce the serum levels of IL-6, hepcidin, and periodontal parameters.

Keywords: Chronic Periodontitis; Hepcidins; Iron; Inflammation.

\section{Introduction}

Periodontal disease is an immunoinflammatory disease of infectious etiology, including gingivitis and periodontitis, which affect the protective and supporting tissues of teeth. ${ }^{1}$ Dental biofilm of microorganisms, primarily gram-negative and anaerobic bacteria such as Porphyromonas gingivalis, Tannerella forsythia, Treponema denticola, and Aggregatibacter actinomycetemcomitans, is reported to be the primary etiologic factor of most periodontal diseases. ${ }^{2}$ Persistent bacterial infection causes the host immune response to disrupt homeostatic mechanisms, resulting in the release of inflammatory mediators, including proinflammatory cytokines (interleukin [IL]-1, IL-6, tumor necrosis factor-alpha [TNF- $\alpha$ ]), proteases (metalloproteases), and prostanoids (prostaglandin E2) by macrophages 
and monocytes. These inflammatory mediators cause bone loss and destruction of the extracellular matrix in the gingiva and also stimulate the production of acute phase proteins, with IL-6 being recognized as the main inductor. ${ }^{3,4,5}$

The low intensity of the chronic inflammatory process in periodontitis has been suggested as a mechanism that determines the biological plausibility in periodontitis and other systemic diseases. ${ }^{6,7}$ Furthermore, evidence indicates that nonsurgical periodontal therapy (NSPT) might influence the development of cardiovascular disease, ${ }^{8}$ rheumatoid arthritis, ${ }^{9}$ type 1 diabetes mellitus, ${ }^{10}$ respiratory disease, ${ }^{11}$ and chronic kidney disease. ${ }^{12}$

Thus, hypothetically, some acute phase proteins whose production is increased during infection and inflammation, such as hepcidin, could be reduced after periodontal therapy. ${ }^{13}$ Hepcidin is a liver-derived hormone that regulates iron metabolism in the body ${ }^{14,15}$ Increased hepcidin synthesis induces iron sequestration in macrophage stores and decreases tissue iron availability by stimulating ferroportin degradation in lysosomes. ${ }^{16,17}$ Body iron load and inflammatory cytokines regulate the production of hepcidin, reflecting the association of this hormone with inflammatory disorders. ${ }^{18,19}$

Prohepcidin, the prohormone of hepcidin, as well as serum IL-6 and high-sensitivity C-reactive protein (hs-CRP) levels, was reported to be significantly decreased after periodontal therapy for chronic periodontitis (CP). ${ }^{13}$ However, the effect of periodontal therapy on serum hepcidin levels remains to be elucidated. Therefore, we aimed to evaluate the effect of NSPT on hepcidin, iron markers, hematological parameters, and inflammatory serum levels in individuals with or without CP.

\section{Methodology}

\section{Study design and groups}

This was an interventional study performed on individuals awaiting care in the outpatient clinics of the Dental School at the Federal University of Maranhão (UFMA), São Luís, Maranhão, Brazil. The study protocol was approved by the Human Research Ethics Committee of the Federal University of Maranhão. The study is registered at ClinicalTrials. gov (NCT02641210).

Inclusion criteria were as follows: individuals of both sexes aged 30-65 years with no other diseases, except for periodontitis, and with at least 20 teeth. Exclusion criteria were as follows: pregnancy, lactation, immunosuppression, smoking or previous smoking habit with less than 10 years since last smoking, orthodontic appliance use, history of steroid and nonsteroidal anti-inflammatory drug use, and antibiotic therapy 3 months before the study and during the research. In addition, those receiving iron replacement therapy for anemia and who received subgingival scaling and periodontal surgery 6 months before the investigation were also excluded.

Initially, 125 volunteers were recruited. Anamnesis was made to obtain personal data, current and previous medical and dental histories, medications in use, and possible alterations in menstrual flow. Data on blood pressure, weight, and height were collected. All study participants received verminosis therapy (single dose of albendazole $400 \mathrm{mg}$; Pratti-Dunaduzzi \& Cia LTDA, Parana, Brazil) to avoid the confounding bias of anemia caused by verminosis in the study sample. After 15 days, blood and urine samples were obtained from individuals who met the initial selection criteria to evaluate the following biochemical markers: total cholesterol, fasting glycemia, triglycerides, albumin, oxalate transaminase, creatinine, iron, ferritin, transferrin saturation, uric acid, hemoglobin, hematimetric indices, hs-CRP, and urinary sediment examination. Patients with alterations in glycemic parameters, liver function, renal function, and lipid profile, confirmed by laboratory tests, were excluded. A total of 62 patients were excluded from the study: 59 for not meeting the inclusion criteria, three for refusing to participate, and three for discontinued intervention. The recruitment phase synthesis is shown in Figure.

Patients were allocated to two groups: $\mathrm{CP}$ group with 33 individuals $\mathrm{CP}$ and control group with 30 individuals without systemic diseases or CP. The groups were selected within a period of six months. Individuals with a diagnosis of $\mathrm{CP}$ had at least two teeth with a probing depth (PD) of $\geq 5 \mathrm{~mm}$ and a clinical attachment level (CAL) of $\geq 6 \mathrm{~mm}$ associated with the presence 


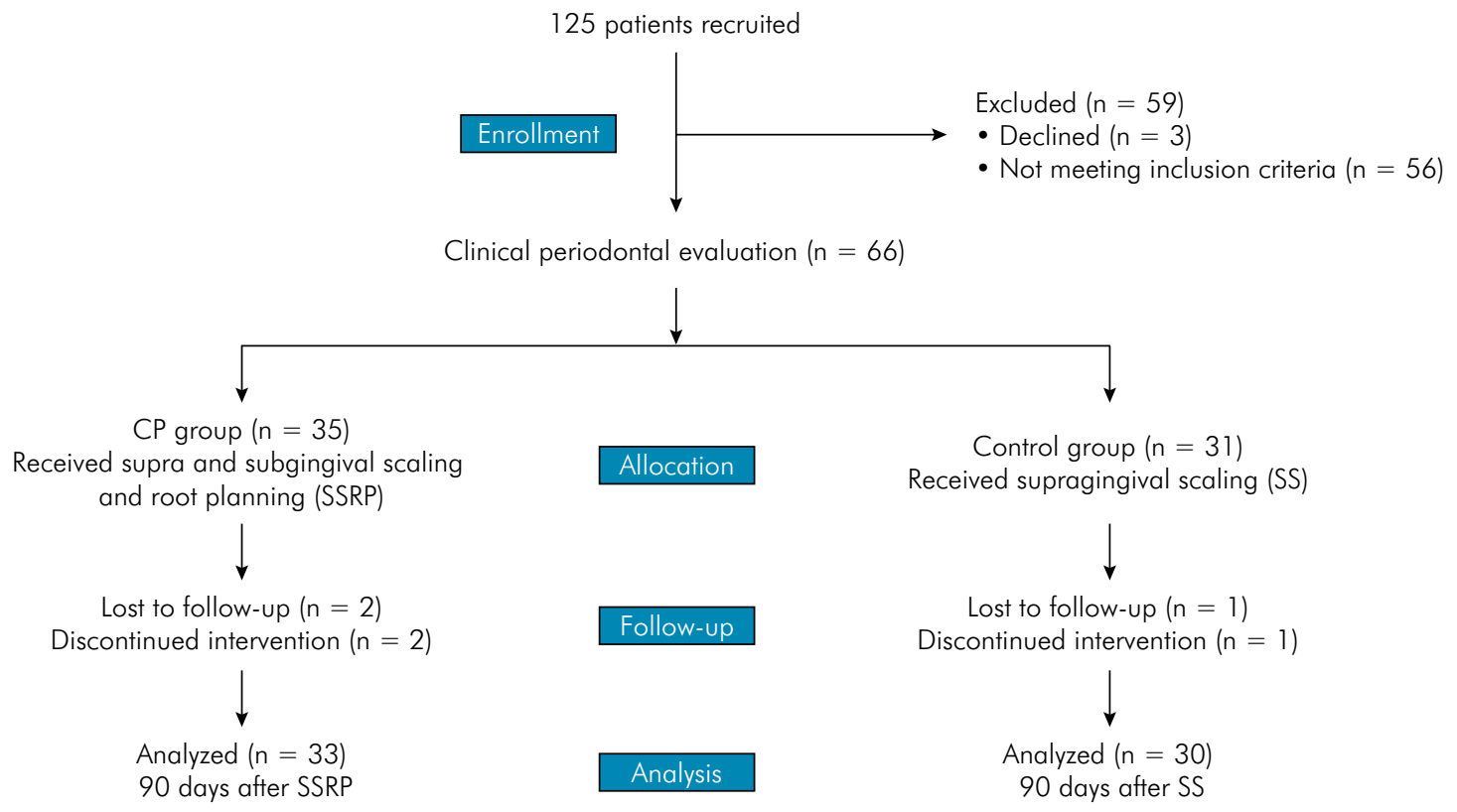

Figure. Flowchart of study recruitment.

of bleeding on probing at the same site, during $30 \mathrm{~s}$ after removal of the periodontal probe. ${ }^{20}$ Individuals without $\mathrm{CP}$ presented no bleeding on probing, $\mathrm{PD}$ up to $3 \mathrm{~mm}$, and visible plaque index (VPI) $\leq 25 \%$.

\section{Periodontal status evaluation}

Periondontal evaluation was performed by a single trained periodontist (SAML) using a Williams periodontal probe (Hu-Friedy ${ }^{\circledR}$, Mgf. Co., Inc., Chicago, USA). The following variables were evaluated: $\mathrm{PD}$, gingival recession (GR), CAL, $\mathrm{VPI}{ }^{21}$ and gingival bleeding index. ${ }^{21} \mathrm{PD}, \mathrm{GR}$, and CAL were recorded at six sites around each tooth (mesiobuccal, midbuccal, distobuccal, distolingual, midlingual, and mesiolingual), ${ }^{22}$ except for the third molars. In both indices, four sites around each tooth (mesiobuccal, midbuccal, distobuccal, and midlingual) were examined. The training process was conducted at the Dental School of UFMA, involving 10 randomly selected patients; the volunteers were examined twice at an interval of 1 week. The intraexaminer agreement coefficient was 0.81 for PD and 0.77 for CAL.

\section{Laboratory analysis}

Twelve-hour fasting venous blood samples $(20 \mathrm{~mL})$ were collected in vacuum tubes and were divided into two portions: a portion of the whole blood was collected in EDTA and a separate aliquot was prepared for blood count evaluation using laser impedance technique (ADVIA 2120 apparatus). The remainder of anticoagulated blood with EDTA was centrifuged for $10 \mathrm{~min}$ at $3000 \mathrm{rpm}$ for plasma separation, aliquoted, and stored at $-70^{\circ} \mathrm{C}$ until further use. Serum samples were collected at baseline and 90 days after periodontal therapy. The following standard laboratory tests were performed: total cholesterol, fasting glycemia, triglycerides, albumin, oxalate transaminase, creatinine, uric acid, hs-CRP, hemoglobin, serum iron, ferritin, transferrin saturation index, hematimetric indices, and urinary sediment examination.

Serum IL-6 and hepcidin levels were assessed by the immunoassay technique using a specific ELISA kit (IBL International, Hamburg, Germany), according to the manufacturer's instructions. The readings were performed using an automatic microplate reader, and the absorbance was read at $450 \mathrm{~nm}$ using a MULTISKAN EX spectrophotometer (Multiskan EX, Labsystems, Bucharest, Romania).

\section{Periodontal therapy}

All participants received an oral hygiene kit and attended a motivational lecture regarding 
instructions on toothbrushing and flossing. The $\mathrm{CP}$ group subjects received NSPT, performed by a single professional, using supragingival and subgingival scaling, and root planing procedures (SSRP), under local anesthesia employing ultrasound device and Gracey and mini-Gracey curettes (5/6, 7/8, 11/12, and 13/14). The therapy was performed in two sessions at an interval of 7 days, with no time limit, according to the need of each periodontal status. In each session, if necessary, individuals received new oral hygiene instructions $(\mathrm{OHI})$.

The control group subjects received supragingival scaling (SS) using an ultrasonic device and periodontal curettes; dental surface polishing; and topical fluoride application. Periodontal maintenance therapy, comprising biofilm control; dental calculus removal, when necessary, through professional prophylaxis; and $\mathrm{OHI}$ reinforcement, were performed at 30,60, and 90 days after the end of NSPT. Ninety days after NSPT, both groups were reassessed using the same baseline clinical periodontal parameters and serum biomarkers.

\section{Statistical analysis}

Data were analyzed using software SAS ${ }^{\circledR}$ system, version 6.11 (SAS Institute, Inc., Cary, USA). Initially, descriptive analysis was performed using measures of frequency, mean, and standard deviation. Categorical variables were compared between the groups using the Chi-square test. The normality of the distribution of continuous variables was verified using the Lilliefors test. The inferential analysis for evaluating the effect of SSRP or SS on variables of the hemogram, inflammatory markers, iron reserves, and periodontal parameters used the paired Student's $t$-test or Wilcoxon's test. For comparison of the corresponding absolute delta (final-initial) between the groups, the Mann-Whitney test was used. The significance level was set at $5 \%$.

\section{Results}

General characteristics of the study groups are presented in Table 1. The CP group, which received SSRP, consisted of 20 women (60.6\%) and 13 men (39.4\%), with a mean age of $41.1 \pm 7.8$ years. The control group, which received SS, consisted of 18 women $(60 \%)$ and 12 men (40\%), with a mean age of $39.5 \pm 8.9$ years. In general, both groups were homogeneous, comparable, and had no statistically significant differences among the following variables: sex, age, systolic blood pressure, diastolic BP (DBP), body mass index, glycemia, and glomerular filtration rate $(\mathrm{p}>0.05)$.

Measures of central tendency and dispersion of serum biomarkers and periodontal variables at baseline and at 90 days after the end of the NSPT (SSRP or SS) are provided in Table 2. The CP group showed a statistically significant decrease in mean corpuscular volume (MCV), mean corpuscular hemoglobin $(\mathrm{MCH})$, IL-6, hepcidin, and erythrocyte sedimentation rate (ESR) levels 90 days after SSRP ( $p \leq 0.05$ ). In the control

Table 1. Distribution of general and medical characteristics of the sample.

\begin{tabular}{|c|c|c|c|c|c|}
\hline $\begin{array}{l}\text { Variable } \\
\text { Age n (\%) }\end{array}$ & \multicolumn{2}{|c|}{ CP group $(n=33)$} & \multicolumn{2}{|c|}{ Control group $(n=30)$} & $\frac{p \text {-value }}{0.65}$ \\
\hline $30-39$ years & 13 & $(39.4)$ & 15 & $(50.0)$ & \\
\hline $40-49$ years & 15 & $(45.4)$ & 12 & $(40.0)$ & \\
\hline 50 years or older & 5 & $(15.2)$ & 3 & $(10.0)$ & \\
\hline Sex & & & & & 0.84 \\
\hline Male & 13 & $(39.4)$ & 12 & $(40.0)$ & \\
\hline Female & 20 & $(60.6)$ & 18 & $(60.0)$ & \\
\hline Systolic blood pressure (mean \pm SD) & 110.6 & \pm 12.2 & 109.7 & \pm 14.0 & 0.78 \\
\hline Diastolic blood pressure (mean \pm SD) & 68.79 & \pm 9.3 & 67.33 & \pm 7.8 & 0.50 \\
\hline Body mass index (mean \pm SD) & 26.1 & \pm 3.7 & 25.9 & \pm 4.0 & 0.78 \\
\hline Glycemia (mean \pm SD) & 84.9 & \pm 8.2 & 83.4 & \pm 7.3 & 0.41 \\
\hline Glomerular filtration rate (mean $\pm \mathrm{SD}$ ) & 105.4 & \pm 24.4 & 104.1 & \pm 26.4 & 0.86 \\
\hline
\end{tabular}

$\mathrm{CP}$ : Chronic periodontitis; $\pm \mathrm{SD}$ : standard deviation. 
group, hemoglobin, hematocrit, MCV, MCH, IL-6, hepcidin, and ESR variables presented a statistically significant difference $(\mathrm{p} \leq 0.05)$ in their initial mean values when compared with those at the end of the 90-day follow-up. However, when alteration variables ( $\Delta$ = final - initial) were compared between CP and control groups, there was no statistical difference, demonstrating intergroup similarity.

The comparison of periodontal clinical parameters at baseline and at the end of the 90-day follow-up is shown in Table 2. In the CP group, a statistically significant difference $(p<0.01)$ was observed between the mean values of all the parameters obtained in the two examinations. In the control group, this difference was only noticed for PD and CAL $(p<0.01)$. CP group showed a greater reduction in all mean values of periodontal parameters, from the first to the last examination (90 days after SSRP), when compared with those of the control group $(p<0.01)$. The relative variation mean of $\mathrm{PD}$ and $\mathrm{CAL}$ in the $\mathrm{CP}$ group was
$-37.5 \%( \pm 9.8)$ and $-37.6 \%( \pm 9.9)$, respectively, whereas, in the control group, this variation was $-27.8 \%( \pm 12)$ and $-29.9 \%( \pm 11.7)$, respectively.

\section{Discussion}

This study evaluated the effect of NSPT (SSRP or SS) on systemic inflammatory response and levels of iron-related serum markers. Based on the biological evidence that host defense cells release immunoinflammatory mediators such as IL-6, TNF$\alpha$, MMPs, and PGE2, and stimulate the production of acute phase proteins such as PCR and hepcidin, in response to periodontal disease, the results of our study are similar to the findings of previous studies. ${ }^{23,24,25,26}$ There was a significant reduction in IL-6 and CRP in both groups (with and without periodontal disease), demonstrating that immunoinflammatory mediators and acute phase proteins decrease after inflammation and infection.

Table 2. Distribution of serum biomarkers and periodontal variables at baseline and 90 days after nonsurgical periodontal therapy and comparative analysis between groups.

\begin{tabular}{|c|c|c|c|c|c|c|c|}
\hline \multirow{3}{*}{ Variable } & \multicolumn{3}{|c|}{ CP Group $(n=33)$} & \multicolumn{3}{|c|}{ Control Group $(n=30)$} & \multirow{3}{*}{$\mathrm{p}$-value ${ }^{2}$} \\
\hline & Baseline & 90 days after SSRP & \multirow{2}{*}{$\mathrm{p}$-value ${ }^{1}$} & Baseline & 90 days after SS & \multirow{2}{*}{$p$-value ${ }^{1}$} & \\
\hline & mean $\pm \mathrm{SD}$ & mean $\pm S D$ & & mean $\pm \mathrm{SD}$ & mean $\pm S D$ & & \\
\hline \multicolumn{8}{|l|}{ Serum biomarkers } \\
\hline Hemoglobin (g/dl) & $13.5 \pm 2.18$ & $13.3 \pm 1.95$ & 0.26 & $14.2 \pm 1.44$ & $13.9 \pm 1.51$ & $<0.01$ & 0.46 \\
\hline Hematocrit (\%) & $41.0 \pm 5.75$ & $40.6 \pm 4.92$ & 0.69 & $43.4 \pm 4.12$ & $42.1 \pm 4.13$ & $<0.01$ & 0.08 \\
\hline MCV (fl) & $87.1 \pm 12.1$ & $86.9 \pm 7.76$ & $<0.01$ & $90.8 \pm 4.28$ & $88.8 \pm 4.08$ & $<0.01$ & 0.35 \\
\hline $\mathrm{MCH}(\mathrm{pg})$ & $29.0 \pm 3.44$ & $28.3 \pm 3.33$ & $<0.01$ & $29.7 \pm 3.44$ & $29.3 \pm 1.65$ & $<0.01$ & 0.21 \\
\hline Serum iron $(\mu \mathrm{g} / \mathrm{dl})$ & $88.8 \pm 38.0$ & $88.5 \pm 34.3$ & 0.96 & $104.6 \pm 31.8$ & $111.9 \pm 34.7$ & 0.26 & 0.50 \\
\hline Transferrin Saturation (\%) & $34.5 \pm 16.1$ & $33.7 \pm 13.8$ & 0.78 & $39.4 \pm 13.5$ & $42.3 \pm 15.0$ & 0.27 & 0.40 \\
\hline Ferritin $(\mathrm{ng} / \mathrm{ml})$ & $125.2 \pm 130.6$ & $117.2 \pm 110.4$ & 0.52 & $127.1 \pm 127.6$ & $138.0 \pm 155.2$ & 0.40 & 0.29 \\
\hline hs-CRP (mg/dl) & $0.27 \pm 0.336$ & $0.24 \pm 0.346$ & 0.17 & $0.25 \pm 0.389$ & $0.23 \pm 0.343$ & 0.84 & 0.38 \\
\hline IL-6 (pg/ml) & $16.0 \pm 8.6$ & $3.9 \pm 3.3$ & $<0.01$ & $14.6 \pm 5.2$ & $2.9 \pm 1.1$ & $<0.01$ & 0.75 \\
\hline Hepcidin (ng/ml) & $65.6 \pm 14.3$ & $36.9 \pm 15.6$ & $<0.01$ & $60.9 \pm 13.0$ & $27.1 \pm 13.0$ & $<0.01$ & 0.09 \\
\hline $\mathrm{ESR}(\mathrm{mm} / \mathrm{h})$ & $6.64 \pm 5.61$ & $10.5 \pm 11.4$ & 0.04 & $5.47 \pm 8.17$ & $8.23 \pm 9.50$ & 0.04 & 0.92 \\
\hline \multicolumn{8}{|l|}{ Periodontal variables } \\
\hline PD $(\mathrm{mm})$ & $2.44 \pm 0.48$ & $1.50 \pm 0.22$ & $<0.01$ & $1.82 \pm 0.24$ & $1.30 \pm 0.17$ & $<0.01$ & $<0.01$ \\
\hline $\mathrm{CAL}(\mathrm{mm})$ & $2.96 \pm 0.54$ & $1.82 \pm 0.31$ & $<0.01$ & $2.05 \pm 0.33$ & $1.44 \pm 0.25$ & $<0.01$ & $<0.01$ \\
\hline VPI (\%) & $8.61 \pm 8.33$ & $1.81 \pm 1.75$ & $<0.01$ & $2.13 \pm 2.62$ & $1.61 \pm 2.01$ & 0.50 & $<0.01$ \\
\hline BoP (\%) & $11.6 \pm 9.90$ & $1.61 \pm 1.92$ & $<0.01$ & $1.18 \pm 1.22$ & $0.89 \pm 0.98$ & 0.38 & $<0.01$ \\
\hline
\end{tabular}

CP: Chronic periodontitis; SSRP: Supragingival and subgingival scaling and root planing Nonsurgical periodontal therapy; SS: supragingival scaling; \pm SD: standard deviation; MCV: Mean corpuscular volume; MCH: Mean corpuscular hemoglobin; hs-CRP: High-sensitivity C-reactive protein; IL: Interleukin; ESR: Erythrocyte sedimentation rate; PD: Probing Depth; CAL: Clinical attachment level; VPI: Visible plaque index; BoP: Bleeding on brobing; $p$-value for comparison between baseline and 90 days in both groups; ${ }^{2} p$-value for comparison of alterations $(\Delta=$ finalinitial) between groups; \pm SD: standard deviation; *Values in bold type are significant at the 0.05 level. 
The hepatic peptide hormone hepcidin regulates the absorption of iron from the diet; plasma iron concentrations and the distribution of iron in the tissues and its increase are linked to the inflammatory and infectious response, leading to a reduction in iron availability. ${ }^{27}$ Hepcidin acts by causing the degradation of its receptor, the ferroportin exporter of cellular iron. Loss of ferroportin decreases plasma iron flux to absorption enterocytes, to macrophages that recycle iron from senescent erythrocytes, and to hepatocytes that store iron, thereby decreasing iron plasma concentration. ${ }^{15,18}$ The malfunctioning of the ferroportin-hepcidin axis contributes to the pathogenesis of different anemias. ${ }^{28}$ Anemia of chronic disease or anemia of inflammation occurs in chronic infections and inflammatory or neoplastic diseases not caused by marrow deficiencies or other diseases. ${ }^{16} \mathrm{It}$ occurs even in the presence of adequate intracellular iron and vitamin store ${ }^{29}$ and is characterized by low levels of serum iron (hypoferremia). ${ }^{30}$ In this context, the findings suggest that the beneficial effect of periodontal intervention seems to be related to its ability to decrease the levels of inflammatory cytokines, and consequently, of serum hepcidin levels.

The results indicate that NSPT led to a reduction in serum IL-6 levels after 3 months of intervention. The reduction of CRP was not so significant as in IL-6. Comparing the groups with $\mathrm{CP}$ and those without $\mathrm{CP}$ to some previous studies, IL-6 and CRP increases were observed even when associated with other systemic diseases. ${ }^{24,31}$ These findings reinforce the effect of periodontal therapy on the reduction of inflammatory markers such as IL-6 and hepcidin.

In a previous short communication with the same baseline data as those of the present study, no statistically significant differences were observed in the level of hepcidin between the groups with or without $\mathrm{CP}^{32}$ whereas another study found differences in serum hepcidin levels between CP and control groups; ${ }^{33}$ however, this study also included patients with type 2 diabetes mellitus, and it presented less strict eligibility criteria, which may have contributed to the inclusion of patients with other systemic diseases, leading to differences between the study findings.

Regarding ESR, a measure that demonstrates inflammatory activity, is a significant parameter related to infection or inflammation. ESR occurred with a greater plasma alteration in several proteins in the $\mathrm{CP}$ group compared with the control group. After periodontal therapy in both groups, a significant increase in ESR was observed after 90 days. These findings are at odds with those obtained by Agarwal et al., ${ }^{34}$ who performed serum biomarker analysis 1 year after periodontal intervention. This may have contributed to the difference in results. In addition, in the present study, IL- 6 levels were reduced, indicating a decrease in inflammatory activity. Therefore, the isolated increase in ESR may be the result of a late treatment response.

Decreased MCV values suggest the presence of microcytosis, which is more commonly caused by iron deficiency anemia. In our study, MCV values were within the reference range for both groups at baseline and at 3 months after NSPT. Despite that, a statistically significant reduction was detected in both groups, even with normal iron levels in all study participants. This finding suggests that other factors may have led to the reduction of MCV after the intervention, which is in accordance with previous study findings. ${ }^{35,36}$

The decrease in $\mathrm{MCH}$ value observed in microcytic anemia is caused by iron deficiency, whereas an increase in $\mathrm{MCH}$ value observed in macrocytic anemia is caused by vitamin deficiency. $\mathrm{MCH}$ values in our study were within the reference range for both groups at baseline and 3 months after NSPT, indicating that anemia is normocytic. The results are consistent with the findings of Pradeep et al..$^{35}$

The hematocrit value was lower in the $\mathrm{CP}$ group and, after periodontal therapy, it was reduced in both groups. In addition, in the group without $\mathrm{CP}$, there was a significant reduction, probably because of a lower number of erythrocytes in individuals with periodontal infection. ${ }^{37,38,39}$

Another important parameter is the iron reserve marker. The results of the present study revealed the influence of periodontal treatment on iron store in individuals without $\mathrm{CP}$, but the increase was not statistically significant. However, in individuals with $\mathrm{CP}$, there was a slight reduction in these reserves, which seems to be compatible with the characteristics of inflammation-related anemia, confirmed by 
normal values of $\mathrm{MCV}$ in the group of individuals with periodontal infection.

There was no significant difference between hemoglobin values for the CP group, whereas a significant reduction was observed, but within the reference values, in the control group after 90 days of periodontal intervention. These results corroborate those reported by Havemose-Poulsen et al. ${ }^{38}$ However, some studies ${ }^{34,35,36,39}$ demonstrated a significant increase in hemoglobin and erythrocytes at 1 year of evaluation.

All the clinical parameters analyzed (PD, CAL, BOP, and VPI) in the two groups were affected similarly, with a significant reduction, showing once again the importance of periodontal therapy. These study findings suggest that supragingival biofilm control is an important factor in modifying inflammatory clinical parameters. ${ }^{40,41}$

The limitation of the present study is the small sample size due to eligibility criteria, which might have reduced the statistical power. In addition, the mean PD and CAL levels in the CP group were low, indicating that these patients did not present an extensive periodontal impairment, thereby limiting the effect of SSRP on changes in biomarker levels. As this study is the first to evaluate the effect of periodontal therapy on serum hepcidin and hemoglobin levels, it may be suggested that periodontal therapy, both SSRP and supragingival biofilm control, influences the reduction of serum IL- 6 and hepcidin levels, as well as of all clinical parameters, by significantly decreasing inflammation and infection in $\mathrm{CP}$ and control groups. Future studies are necessary to better elucidate the processes that occur during the inflammation phase of periodontal tissues and the possible beneficial effects of periodontal therapy on anemia.

\section{Conclusion}

Our findings suggest that periodontal therapy, both supragingival and subgingival scaling and root planing and only supragingival biofilm control, may reduce serum IL-6 and hepcidin levels, thereby reinforcing the positive effects of periodontal care on systemic health.

\section{Acknowledgements}

The authors would like to thank the Research Support Foundation of Maranhão State (FAPEMA) for the logistical and financial support.

\section{References}

1. Kinane DF, Stathopoulou PG, Papapanou PN. Periodontal diseases. Nat Rev Dis Primers. 2017 Jun;3(1):17038. https://doi.org/10.1038/nrdp.2017.38

2. Van der Velden $U$. What exactly distinguishes aggressive from chronic periodontitis: is it mainly a difference in the degree of bacterial invasiveness? Periodontol 2000. 2017 Oct;75(1):24-44. https://doi.org/10.1111/prd.12202

3. Cekici A, Kantarci A, Hasturk H, Van Dyke TE. Inflammatory and immune pathways in the pathogenesis of periodontal disease. Periodontol 2000. 2014 Feb;64(1):57-80. https://doi.org/10.1111/prd.12002

4. Becerik S, Öztürk VO, Atmaca H, Atilla G, Emingil G. Gingival crevicular fluid and plasma acute-phase cytokine levels in different periodontal diseases. J Periodontol. 2012 Oct;83(10):1304-13. https://doi.org/10.1902/jop.2012.110616

5. Forner L, Nielsen CH, Bendtzen K, Larsen T, Holmstrup P. Increased plasma levels of IL- 6 in bacteremic periodontis patients after scaling. J Clin Periodontol. 2006 Oct;33(10):724-9. https://doi.org/10.1111/j.1600-051X.2006.00964.x

6. Noack B, Kipping T, Tervahartiala T, Sorsa T, Hoffmann T, Lorenz K. Association between serum and oral matrix metalloproteinase- 8 levels and periodontal health status. J Periodontal Res. 2017 Oct;52(5):824-31. https://doi.org/10.1111/ire.12450

7. Kinane DF, Zhang P, Benakanakere M, Singleton J, Biesbrock A, Nonnenmacher $C$, et al. Experimental gingivitis, bacteremia and systemic biomarkers: a randomized clinical trial. J Periodontal Res. 2015 Dec;50(6):864-9. https://doi.org/10.1111//re.12280

8. Holmlund A, Lampa E, Lind L. Poor response to periodontal treatment may predict future cardiovascular disease. J Dent Res. 2017 Jul;96(7):768-73. https://doi.org/10.1177/0022034517701901

9. Silvestre FJ, Silvestre-Rangil J, Bagán L, Bagán JV. Effect of nonsurgical periodontal treatment in patients with periodontitis and rheumatoid arthritis: A systematic review. Med Oral Patol Oral Cir Bucal. 2016 May;21(3):e349-54. https://doi.org/10.4317/medoral.20974 
The effect of nonsurgical periodontal therapy on hepcidin and on inflammatory and iron marker levels

10. Altamash M, Klinge B, Engström PE. Periodontal treatment and HbAlc levels in subjects with diabetes mellitus. J Oral Rehabil. 2016 Jan;43(1):31-8. https://doi.org/10.1111/joor.12339

11. Shen TC, Chang PY, Lin CL, Chen CH, Tu CY, Hsia TC, et al. Periodontal treatment reduces risk of adverse respiratory events in patients with chronic obstructive pulmonary disease: a propensity-matched cohort study. Medicine (Baltimore). 2016 May;95(20):e3735. https://doi.org/10.1097/MD.0000000000003735

12. Grubbs V, Garcia F, Jue BL, Vittinghoff E, Ryder M, Lovett D, et al. The Kidney and Periodontal Disease (KAPD) study: A pilot randomized controlled trial testing the effect of non-surgical periodontal therapy on chronic kidney disease. Contemp Clin Trials. 2017 Feb;53:143-50. https://doi.org/10.1016/i.cct.2016.12.017

13. Vilela EM, Bastos JA, Fernandes N, Ferreira AP, Chaoubah A, Bastos MG. Treatment of chronic periodontitis decreases serum prohepcidin levels in patients with chronic kidney disease. Clinics (São Paulo). 2011;66(4):657-62. https://doi.org/10.1590/S1807-59322011000400022

14. Silva B, Faustino P. An overview of molecular basis of iron metabolism regulation and the associated pathologies. Biochim Biophys Acta. 2015 Jul;1852(7):1347-59. https://doi.org/10.1016/j.bbadis.2015.03.011

15. Nemeth E, Tuttle MS, Powelson J, Vaughn MB, Donovan A, Ward DM, et al. Hepcidin regulates cellular iron efflux by binding to ferroportin and inducing its internalization. Science. 2004 Dec;306(5704):2090-3. https://doi.org/10.1126/science.1104742

16. Camaschella C. New insights into iron deficiency and iron deficiency anemia. Blood Rev. 2017 Jul;31(4):225-33. https://doi.org/10.1016/i.blre.2017.02.004

17. Rochette L, Gudjoncik A, Guenancia C, Zeller M, Cottin Y, Vergely C. The iron-regulatory hormone hepcidin: a possible therapeutic target? Pharmacol Ther. 2015 Feb;146:35-52. https://doi.org/10.1016/i.pharmthera.2014.09.004

18. Ganz T. Hepcidin, a key regulator of iron metabolism and mediator of anemia of inflammation. Blood. 2003 Aug;102(3):783-8. https://doi.org/10.1182/blood-2003-03-0672

19. Zhang X, Rovin BH. Beyond anemia: hepcidin, monocytes and inflammation. Biol Chem. 2013 Feb;394(2):231-8. https://doi.org/10.1515/hsz-2012-0217

20. Reinhardt RA, Payne JB, Maze CA, Patil KD, Gallagher SJ, Mattson JS. Influence of estrogen and osteopenia/osteoporosis on clinical periodontitis in postmenopausal women. J Periodontol. 1999 Aug;70(8):823-8. https://doi.org/10.1902/jop.1999.70.8.823

21. Ainamo J, Bay I. Problems and proposals for recording gingivitis and plaque. Int Dent J. 1975 Dec;25(4):229-35.

22. Armitage GC. The complete periodontal examination. Periodontol 2000. 2004;34(1):22-33. https://doi.org/10.1046/i.0906-6713.2002.003422.x

23. Forner L, Nielsen CH, Bendtzen K, Larsen T, Holmstrup P. Increased plasma levels of IL-6 in bacteremic periodontis patients after scaling. J Clin Periodontol. 2006 Oct;33(10):724-9. https://doi.org/10.1111/j.1600-051X.2006.00964.x DUPLICATA DA 5

24. D'Aiuto F, Nibali L, Parkar M, Suvan J, Tonetti MS. Short-term effects of intensive periodontal therapy on serum inflammatory markers and cholesterol. J Dent Res. 2005 Mar;84(3):269-73. https://doi.org/10.1177/154405910508400312

25. Gomes-Filho IS, Freitas Coelho JM, da Cruz SS, Passos JS, Teixeira de Freitas CO, Aragão Farias NS, et al. Chronic periodontitis and C-reactive protein levels. J Periodontol. 2011 Jul;82(7):969-78. https://doi.org/10.1902/jop.2010.100511

26. Yazdi FK, Karimi N, Rasouli M, Roozbeh J. Effect of nonsurgical periodontal treatment on C-reactive protein levels in maintenance hemodialysis patients. Ren Fail. 2013;35(5):711-7. https://doi.org/10.3109/0886022X.2013.777890

27. Ganz T. Molecular control of iron transport. J Am Soc Nephrol. 2007 Feb;18(2):394-400. https://doi.org/10.1681/ASN.2006070802

28. De Domenico I, Ward DM, Kaplan J. Hepcidin regulation: ironing out the details. J Clin Invest. 2007 Jul;117(7):1755-8. https://doi.org/10.1172/JCl32701

29. Nemeth E, Ganz T. The role of hepcidin in iron metabolism. Acta Haematol. 2009;122(2-3):78-86. https://doi.org/10.1159/000243791

30. Nemeth E, Rivera S, Gabayan V, Keller C, Taudorf S, Pedersen BK, et al. IL-6 mediates hypoferremia of inflammation by inducing the synthesis of the iron regulatory hormone hepcidin. J Clin Invest. 2004 May;113(9):1271-6. https://doi.org/10.1172/JCI200420945

31. Leivadaros E, van der Velden U, Bizzarro S, ten Heggeler JM, Gerdes VE, Hoek FJ, et al. A pilot study into measurements of markers of atherosclerosis in periodontitis. J Periodontol. 2005 Jan;76(1):121-8. https://doi.org/10.1902/jop.2005.76.1.121

32. Carvalho RC, Leite SA, Rodrigues VP, Pereira AF, Ferreira TC, Nascimento FR, et al. Chronic periodontitis and serum levels of hepcidin and hemoglobin. Oral Dis. 2016 Jan;22(1):75-6. https://doi.org/10.1111/odi.12373

33. Guo LN, Yang YZ, Feng YZ. Serum and salivary ferritin and Hepcidin levels in patients with chronic periodontitis and type 2 diabetes mellitus. BMC Oral Health. 2018 Apr;18(1):63. https://doi.org/10.1186/s12903-018-0524-4

34. Argawal N, Kumar VS, Guijari SA. Effect of periodontal therapy on hemoglobin and erythrocyte levels in chronic generalized periodontitis patients: an interventional study. J Indian Soc Periodontol. 2009 Jan;13(1):6-11. https://doi.org/10.4103/0972-124X.51887

35. Pradeep AR, Anuj S, Raju A. Anemia of chronic disease and chronic periodontitis: does periodontal therapy have an effect on anemic status? J Periodontol. 2011 Mar;82(3):388-94. https://doi.org/10.1902/jop.2010.100336

36. Gokhale SR, Sumanth S, Padhye AM. Evaluation of blood parameters in patients with chronic periodontitis for signs of anemia. J Periodontol. 2010 Aug;81(8):1202-6. https://doi.org/10.1902/jop.2010.100079

37. Kolte RA, Kolte AP, Deshpande NM. Assessment and comparison of anemia of chronic disease in healthy subjects and chronic periodontitis patients: A clinical and hematological study. J Indian Soc Periodontol. 2014 Mar;18(2):183-6. https://doi.org/10.4103/0972-124X.131321 
38. Havemose-Poulsen A, Westergaard J, Stoltze K, Skjødt H, Danneskiold-Samsøe B, Locht H, et al. Periodontal and hematological characteristics associated with aggressive periodontitis, juvenile idiopathic arthritis, and rheumatoid arthritis. J Periodontol. 2006 Feb;77(2):280-8. https://doi.org/10.1902/jop.2006.050051

39. Naik V, Acharya A, Deshmukh VL, Shetty S, Shirhatti R. Generalized, severe, chronic periodontitis is associated with anemia of chronic disease: a pilot study in urban, Indian males. J Investig Clin Dent. 2010 Nov; (2):139-43. https://doi.org/10.1111/j.2041-1626.2010.00028.x

40. Gomes SC, Romagna R, Rossi V, Corvello PC, Angst PD. Supragingival treatment as an aid to reduce subgingival needs: a 450-day investigation. Braz Oral Res. 2014;28(1):1-7. https://doi.org/10.1590/S1806-83242014.50000004

41. Butze JP, Angst PD, Oppermann RV, Gomes SC. Periodontal risk and recall interval evaluation after a program of comprehensive supragingival plaque control. Quintessence Int. 2015 Oct;46(9):765-72. https://doi.org/10.3290/i.qi.a34176 